\title{
Blockchain as an innovative digitalization achievement in logistics of eco-tourism
}

\author{
Ekaterina Arbatskaya ${ }^{1,{ }^{*}}$ and Lyubov Khoreva ${ }^{1}$ \\ ${ }^{1}$ St. Petersburg State University of Economics, St. Petersburg, Sadovaya st., 21. Russia
}

\begin{abstract}
The main trend of development of modern society is named - it is digitalization that is causing global changes in industries, companies, processes, business models. Recently, an increasing penetration of the latest information technologies into all spheres of modern society, including tourism, which is currently one of the fastest growing areas in Russia, can be observed. The study of logistic in tourism is one of the promising areas of the modern economy, and, at the same time, blockchain is the main trend of digitalization. Despite the novelty of the trend of digitalization of tourism logistics, there is a growing awareness of its importance for economic and social development in Russian and in international practice. The definition of concept and content of the blockchain technology are considered. The main goal of getting familiar with the blockchain technology and highlighting its importance is achieved. The expediency of use is justified and examples of practical application of blockchain technologies in tourism logistics are considered. The assumption is made that the interest of using blockchain technology will increase in the nearest future.
\end{abstract}

\section{Introduction}

Production and trade relations, the structure of the economics, new requirements for communication processes, computing power, information systems and technologies are changing with the transition to a qualitatively new level of economic structure - the digital economy and the introduction of new digital technologies [1]. It leads to a technological breakthrough both in the information sphere and in many other areas [2].

The study of the logistics of tourism services is one of the promising areas of the modern economics at the moment [3] that is an information-intensive activity and is ideally suitable for introducing innovative digital technologies [4].

At the same time, the blockchain is one of the main trends of digitalization and is the trend the whole future now. The blockchain system has been relatively recently appeared.

The blockchain technology is a well-structured database with specific rules for building chains of transactions and access to information that exclude data theft, fraud, violation of property rights, etc.

In other words, the blockchain is a software sequence of activities that allows privately and securely exchange data through computer networks [5]. The main idea of the

\footnotetext{
* Corresponding author: arbaton@mail.ru
} 
blockchain technology is a chain of blocks with information about each taken action (transaction register), that is then stored in each unit of computers' network. For example, when purchasing a product or service, information about the origin of the product, the quality of the service provided, the price at the time of purchase, the seller, the date of the transaction, and other information are recorded in the database as a block [6].

Each piece of information is assigned with a unique multi-digit numeric code in order to protect and simplify record keeping. As a result, each supply chain link records the operations it performs as a block with information, besides, each block contains information about each previous link. Moreover, the blockchain technology implies a certain structure for data recording and accounting, which organizes the execution of various operations.

Therefore, the aim of this article is to show the importance of the blockchain technology that promotes a personalized approach to the process of providing tourism services by creating a trusted digital environment due to increasing the reliability of activities and transactions, ensuring the reliability of information, improving the quality of provided services.

\section{Materials and Methods}

Many authors have devoted their works to the main trends in the development of logistics as a scientific direction and practical activity. Burning issues of digitalization of logistics in tourism are also considered by many Russian and foreign scientists.

The theoretical basis of this study is formed by the results of fundamental and applied researches by leading scientists on economics and logistics, as well as research works related to the use of digital technologies in tourism logistics, and blockchain technology is one of which.

The collection, accumulation and processing of materials was carried out using empirical research methods (observation, comparison) and methodological theoretical studies (analysis, synthesis, personal author forecasting).

\subsection{The future of the blockchain through the lens of scientific research}

According to research data, only $1 \%$ of organizations are using the blockchain technology in their supply chain operations at the moment, and only $35 \%$ are currently exploring the possibility of using blockchain technology. One of the reasons for such low indicators is explained by that the technology is too new, due to the fact that awareness of this technology has begun to appear only in the last couple of years [7]. It is possible to assume that the information about the technology will spread and, as a result, the interest of enterprises in its application will increase.

Blockchain promotes efficiency and reliability in data security, transparency and security from outside interference information exchange. Information that was entered into the system can not be already change, and its storage is carried out without the help of centralized management.

Logistics of tourism is defined as the science of planning, controlling and management of operations that are performed in the process of forming a service, bringing the finished service to the consumers in accordance with their interests and requirements, as well as in the process of transferring, storing and processing relevant information regarding a tourist service [8].

Based on this definition, it is worth to notice that logistics chains in tourism often cover numerous stages of integration of various streaming processes. So that, quite often there is a situation when it is difficult to follow all the events of the logistics chain of the process of 
providing tourist services and, if it is necessary, quickly respond to unforeseen circumstances. Moreover, due to lack of transparency, it becomes extremely difficult to identify illegal activities that may occur at any logistic stage.

The relevance of the introduction of the blockchain technology for logistics of tourism is determined by the fact that the supply chain of tourism services provided to consumers seems to be a single process that includes various types of logistics activities. The availability of both material, information, financial resources, and human is a main feature of the flow processes in the supply chains of tourism services. Such types of supply chain acquire new properties that include the following: the service is not produced, but provided to the consumer; social significance in the logistics services of the tourism industry prevails over economic [9].

In this way, the integration of logistics processes in the supply chain of the tourism industry and the quality of given services provided by the tour operator determine the effectiveness of all operations aimed at meeting customer needs in general [10]. Based on this, tourist enterprises are paying more attention to the whole process in aggregate at the moment, and not to optimize individual logistics operations only.

\subsection{A look into the future through a trip into the history of information technology}

The trend of gradual digitalization of logistics technologies in tourism can be traced by events characteristic of a specific time interval. The Internet only appeared in Russia in 1983-1985 years, and only basic technologies of working with information resources were used. Then there were quite large databases in the field of tourism, electronic logistic systems and technologies began to be used that provide for the automation of logistics processes of tourism enterprises later in 2000.

Currently, the integration of information flows based on modern data processing and transmission methods is the dominant direction in the development of information systems and digital technologies in logistics that also remains relevant for subsequent time periods [11].

The relevance of the introduction and use of information systems and digital technologies in the logistics of tourism services characterized by the increasing volume of data to be processed. The scientific and technical progress of digital technologies has become an important element in more efficient logistics management of tourism enterprises. The speed of data processing and obtaining the necessary information is the deciding factor in the management. Recently, the information is increasingly called "strategic raw materials", moreover, a creation of large single databases appears and it is called Big Data.

The modern information systems and digital technologies are based on the use of information storage concepts and intelligent data processing significantly and increase labor productivity, efficiency of logistics management of a tourism enterprise and its financial success.

The use of information technology systems by each tourism logistics segment is important for all participants in the logistics system. It is easier to achieve improved quality indicators of logistic processes in the field of tourism and increased efficiency of tourism enterprises through the integration of the constituent functions of logistics, its segments and properties, logistic flows, as well as information systems and technologies,

In addition, several information systems are currently presented on the modern digital technology market in the tourism industry, that allows to automate the internal activities of a travel company and integrate its internal processes [12]. The joint proper use of these 
software systems provides a positive synergistic effect in the logistics of the tourism industry and in the economic activities of tourism enterprises in general.

Regarding further development, in the coming decades, for example, in the time interval 2026-2035 years, it is possible to predict the emergence of digital technologies that allow a model experiment that simulates a full "experimental race", as well as the emergence of digital logistical simulation platforms that provide demand forecasting, price study, analysis of the choice of options for the route and the full logistic support of the process of providing services by a tourist enterprise [9].

Trying to predict the development of future time periods, up to 2050, it is possible to assume that further digitalization of logistics technologies in tourism will lead to the robotization of logistics services: the use of drone robots monitoring the optimal options for providing quality tourism services, as well as managing all related logistics operations in tourism [13].

So that, the relevance of digital support for logistics in tourism is obvious. Taking into consideration the interests of the functioning of all logistics subsystems, and in turn, the knowledge of the interaction of individual elements enhances the effectiveness of the functioning of the logistics system in the whole is really important for a tourism organization [14]. The blockchain technology can help to achieve such aims.

\subsection{Looking to the future of blockchain technology}

The potential opportunities of the blockchain can help to solve the above issues. However, providing a positive effect from its use is possible only with access to the network for all participants in the logistics chain that is an important aspect of the blockchain technology.

It is worth noting the expediency of integrating the blockchain into this industry, despite the fact that the use of the blockchain in the logistics of the tourism industry is still not sufficiently developed because of the possible risks and disadvantages that include: the lack of a legislative framework that allows to resolve controversial issues in the process of working with blockchain technology; the need to transfer all operations with information into a "virtual environment" that is not fully possible at the moment; the difficulty of combining and simultaneously controlling a large number of participants, as well as low awareness among enterprises about innovative technology [5].

According to experts of the modern economic market, the blockchain technology is able to solve problems specific to the tourism logistics industry, including the elimination of intermediaries and a significant change in the existing models for conducting logistics operations [15]. The logistics system based on blockchain technology may be simpler due to the absence of intermediate links in it and a reduction in the amount of information flow and possible mistakes that were made. Such system gives the possibility to strengthen the interaction between participants in the process of providing tourism services, and its main feature may be the integrity and trust of participants to each other.

Moreover, the transition to decentralized public and private registries except for fraud can reduce systemic risks. The decision-making process itself at each stage of the tourism enterprise's activities is accelerated, one-time access to information is provided, and the possibility of joint forecasting of further actions appears thanks to increasing the level of trust among participants in the process of providing tourism services.

Digitalization is one of the brightest trends of the modern society. Analyzing the trends of future development and considering the time interval 2018-2025, it is possible to approve that humanity has entered in such a stage of its development where digital technologies play a decisive role in all areas of activity and become the most important factor for sustainable development and economic growth [11]. Concerning this fact, more and more attention is paid to blockchain technologies. 


\section{Results}

\subsection{Practical application of blockchain technology}

In the future, the introduction of blockchain technologies in the management of the logistics activities of tourism enterprises can be noted the following advantages and its practical application that is shown in figure $1[4 ; 6]$ :

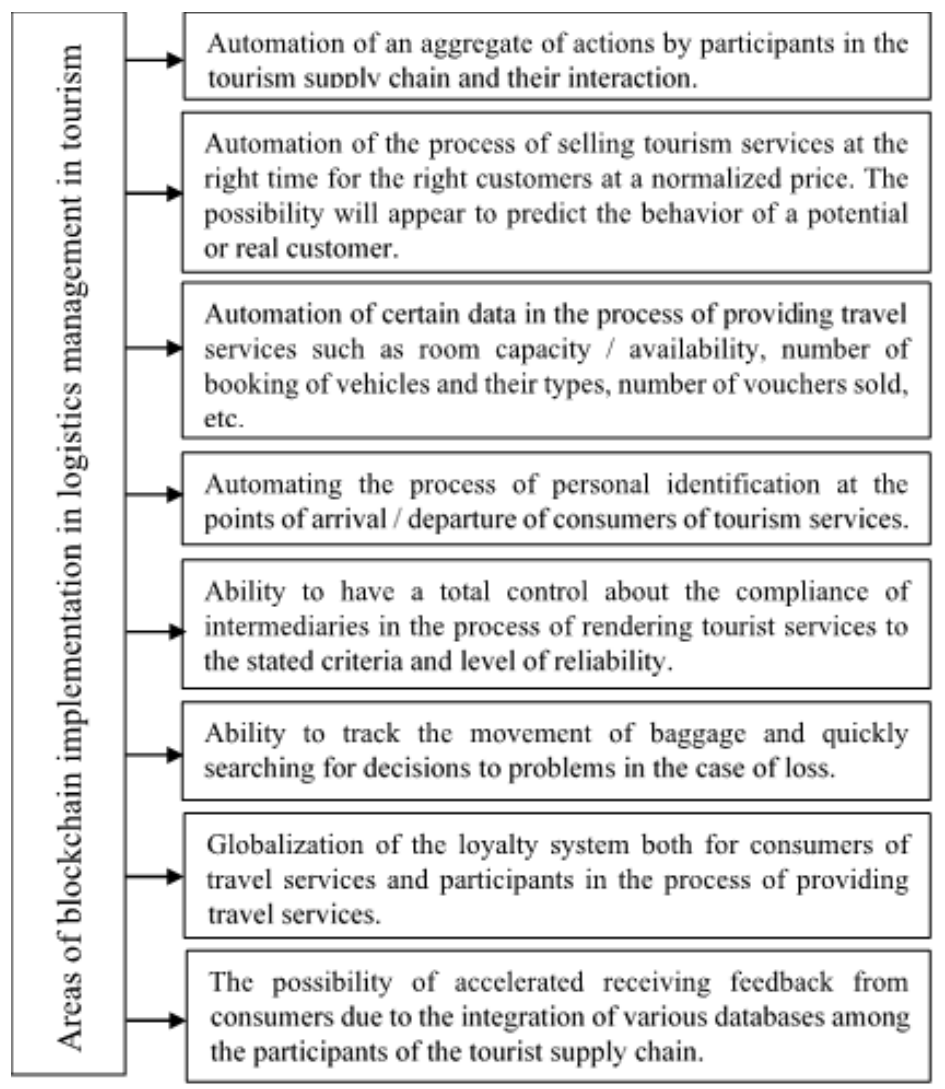

Fig. 1. The blockchain in the management of the logistics in tourism

The use of personalized service models based on the blockchain technologies can be used both by tourists themselves and by tourist companies as well. Further, we have systematized the structure of forms of joint use of blockchain technologies by business entities, on the one hand, and tourists, on the other, that is shown in figure 2. 


\begin{tabular}{|c|}
\hline The use by tourists \\
\hline $\begin{array}{c}\text { The reliability of orders is } \\
\text { digital space } \\
\text { increased by digital trusted } \\
\text { environment }\end{array}$ \\
reduced, and the quality of its \\
provision is improved \\
The processes of checking \\
reliability of the service \\
provider are being automated
\end{tabular}

Fig. 2. The sharing use of blockchain technology in tourism logistics by consumers and service providers

\section{Discussion}

\subsection{The significance and potential of blockchain technology}

Thus, summarizing the above, the transition of tourism enterprises to work with blockchain will have a definite impact on this industry. As previously noted, the blockchain is a new technology, far from fully studied and accepted by modern society. There is a sufficient number of potential issues, technical and psychological barriers that may arise with further improvements and implementations of the blockchain system in the activities of enterprises. The need for a huge amount of resources, its high cost, the likelihood of errors and inconsistencies, the lack of a legislative base and criteria for standardization of the blockchain technology, the lack of the necessary capacity to constantly update the database, drastic changes to existing approaches to work in the tourism market, etc. - all these factors retard the development of blockchain technologies.

However, at the same time, it can be concluded about the significant advantages of the blockchain technology for the tourism industry logistics This technology will help to achieve maximum effect with minimal changes is in the logistics of tourism that emphasizes the desirability of its further dissemination in this area.

The potential of blockchain technologies related to tourism logistics lies in transparency, reliability and efficiency, in reducing and simplifying workflow, speeding up the transfer of information and all kinds of streaming processes, in the absence of the need for an intermediary as a coordinator of logistics processes due to their automation and integration. 
Therefore, it can be assumed that, blockchain technologies will find their application and are widely used in tourism logistics in the nearest future, being an innovative tool and achievement of digitalization [4], which is currently one of the priority development strategies in the world.

\section{Conclusions}

As a result of our scientific research, we came to the conclusion that the digital transformation of logistics in tourism is a new form of communication between producers and consumers of tourism services becoming a source of competitive advantages for tourism organizations and an effective way to manage tourist flows.

Competitive advantages will be gained by those tourism enterprises that can implement the process of customization in the process of providing services in the best way turning the consumer from among potential customers not only into real ones, but also into loyal and permanent ones, thereby ensuring its sustainability in the long term. perspective based on consistently high indicators of profit and profitability that is especially important in the current crisis [16].

The formation of a new market of tourism services based on the digitalization of all processes is seen today as an opportunity not only to preserve this area of economic activity but also to develop it through new opportunities that blockchain technologies provide. These opportunities are automatization the entire set of elements of the interaction chain of participants creating a tourism product; ensuring transparency and security of the process of selling tourism products and services taking into account the time component of the service process; increasing the level of management of a tourist enterprise; quality control of services provided to the tourist by all participants in the chain of creating a tourist product and providing the service with the declared level of reliability; quick solution of tourist problems at all stages of consumption of a tourist product (booking, flight, accommodation, excursion services, etc.); creation of global systems of loyalty both for consumers of travel services and for all participants in the process of creating value for the consumer; ensuring effective communications and receiving feedback from the clients; increasing the speed and objectivity of information analysis at all stages of working with tourists as well as the possibility of further increasing customer focus and personalizing travel services.

The outcomes of the study are:

- the history of the development of information technologies is highlighted;

- the concept and content of blockchain technology has become known;

- the views and hypotheses of scientists regarding the future of digitalization are given;

- the options for the practical application of blockchain technology are considered and its the benefits are highlighted;

- the discussion about the significance and potential of blockchain technology is held.

To sum up, therefore, the main objective of the study to show the importance of blockchain technology that promotes a personalized approach to the process of providing tourism services has been achieved.

\section{References}

1. G. Karpova, A. Malinin, D. Andreeva, E. Valeeva, V. Tkachev, Problems of the Modern Economy 2(62) (2017)

2. Y. Chen, China Economic Review 62, 101482 (2020)

3. C. Reichstein and R.-C. Härting, Procedia Computer Science 126, 1484 (2018) 
4. E. Arbatskaya, L. Khoreva, and V. Shcherbakov, Economics and Management 26, 255 (2020)

5. V. Scherbakov, V. Minakov, O. Lobanov, and T. Minakova, 18th International Multidisciplinary Scientific GeoConferences SGEM. Conference proceedings, 437-444 (2018)

6. V. Shcherbakov, G. Silkina, Economy and Entrepreneurship 5-1 (82), 1090 (2017)

7. Y. Kayikci, Procedia Manufacturing 21, 782 (2018)

8. L. Marques and C. Borba, Tourism Management Perspectives 24, 86 (2017)

9. E. Arbatskaya, Audit and Financial Analysis 2, 429 (2018)

10. S. Uvarov, Bulletin of the Russian Academy of Natural Sciences 17(4), 145 (2013)

11. B. Burroughs and W. J. Burroughs, Technology in Society 62, 101277 (2020)

12. C. Bassano, S. Barile, P. Piciocchi, J. C. Spohrer, F. Iandolo, and R. Fisk, Cities 87, 10 (2019)

13. S. B. Hojeghan and A. N. Esfangareh, Procedia - Social and Behavioral Sciences 19, 308 (2011)

14. X. Li and R. Law, Tourism Management Perspectives 33, 100608 (2020)

15. A. Byichuk, Economic Environment 2(20), 14 (2017)

16. T. V. Cherevichko and T. V. Temyakova, Bulletin of the Saratov University. Series: Economics. Control. Right 19(1), 59 (2019) 